\title{
Critical Spatial Thinking in Women's Resilience for An Inclusive City
}

\author{
Isabel Cristina Carvalho
}

\author{
CIAC-UAb Research Centre in Arts and Communication, Aberta University, Portugal
}

\begin{tabular}{l} 
ARTICLE INFO \\
\hline Keywords: \\
Collaborative mapping \\
Equal rights \\
Feminism \\
Gender biases \\
Inclusive city \\
Women empowerment
\end{tabular}

\section{Introduction}

In the global context, in terms of gender equality, the Beijing Declaration (1995) and its Platform for Action were established to eliminate obstacles to women's active participation and promote their empowerment - as a strategic area to promote human rights and citizenship and more just society. However, in 2021, twenty-six years later, the problem persists. Although there was a significant achievement at the legislative level, it is still not reflected in real changes at the level of practices, attitudes, and mentalities, with an increase of accusations of gender violence and discriminatory acts against women. On March 4, 2020, the UN, through the United Nations Development Program - Human Development Reports, released its "Social Norms and Gender Index" study (United Nations Development Programme, 2020) related to seventy-five countries (making up about $80 \%$ of the world's population), revealing that prejudice against women is widespread. Nine out of ten men and $86 \%$ of women have some prejudice against women. This study concluded that social norms are a real but invisible

\footnotetext{
* Corresponding author E-mail address: isabel.carvalho@uab.pt Sciences, 4(1), 32-40. https://doi.org/10.33422/jarss.v4i1.688
}

(C) The Author(s). 2021 Open Access. This article is distributed under the terms of the Creative Commons Attribution 4.0 International License, which permits unrestricted use, distribution, and redistribution in any medium, provided that the original author(s) and source are credited.

\begin{abstract}
Gender continues to affect how urban spaces are perceived and experienced. Girls and women continue to experience sexual environments. Reinforcing the concept "Right to the City" of Henri Lefebvre (1991) and David Harvey (2008), this paper aims to explore the need to promote critical spatial thinking to demystify gender participate and contribute to the (re)design of an inclusive city. People are social products whose values and beliefs are shaped by society, often inequalities. It is crucial to enable and encourage critical spatial thinking about women's environment to understand and recognise existing of the situation in which we live. Several authors refer to critical thinking as fundamental to the empowerment process, pointing out that by inequality. The exercise of critical spatial thinking also highlights the need for new communication processes that recognise and enhance the urban spaces. It will enrich a more active collective voice, increase civic participation necessary to build safer and gender-equal spaces in urban life.
\end{abstract}


obstacle, a deep-rooted prejudice against the everyday practice of full equality in both men and women.

People reflect values and beliefs shaped by society. Society is not always in favour of equality or sometimes unaware of situations of inequality, often replicating social practices, norms and behaviours that perpetuate patriarchy. On the other hand, the conception and design of cities have never been gender-neutral. In a world where the needs of the stereotypical white working man have historically been considered the norm and standard, without taking diversity into account, the majority of the population has often been excluded. Today we still witness low participation of women in decisions related to urban planning.

Gender continues to influence how urban spaces are perceived and experienced. Women and girls continue to suffer sexual harassment to feel unsafe and limited in their mobility in the territory. This paper highlights the need for collective actions of collaborative mapping, instigating the exercise of critical spatial thinking for reflection and awareness in processes of female empowerment.

\section{Methodology}

In this exploratory research, a selection of collaborative mapping actions acting in the area of equal gender rights was carried out. A literary selection was made in scientific research platforms, as well as in internet search engines using the keywords "collaborative mapping", "critical spatial thinking", "mapactivism", "feminist activism", and "active citizenship". From this search, four actions of urban intervention through collaborative mapping dealing with the relationship between women and urban spaces were selected. These four actions represent four complementary approaches to feminist activism. They also reflect how women feel in certain places in the cities where they live, identifying, sharing and georeferencing moments and feelings, mapping places considered "good" and "bad". These mappings, created collaboratively, rose from critical spatial thinking exercises. It was possible to visualize and relate places where women were victims of aggression and violence, reflect on the representation of female figures in the streets of cities (toponymy), and use these spaces as scenarios for performances of performances protesting against violence women.

\subsection{Gender perspective in thinking the city}

Thinking about a city from a gender perspective challenges the assumption that planning is neutral and argues that territorial organization has been configured through the values of a patriarchal society, without considering its citizens' diversity, and where urban spaces contribute to perpetuating these values. Furthermore, in these processes, women are omitted or have little participation in decision-making processes.

Since urban space is a social construction, its use and experience are therefore different depending on gender. People live spaces differently because they have different needs and experiences. Safety, for example, is central to a woman's experience of the city. For this reason, it is crucial to identify the fracturing points in cities to question and show how different urban territories are seen and lived, taking gender diversity into account. Critical spatial thinking is highlighted here as an important step in the process of women's empowerment.

\subsection{Critical spatial thinking and social engagement}

Spatial thinking is part of our everyday life, so natural that it happens without our awareness of it most of the time. Michael Goodchild \& Donald Janelle (2010) consider it a basic and essential skill in modern society. In addition, several authors consider critical thinking fundamental to the process of empowerment and social engagement, pointing out that by exercising critical reflection on the situation they experience, women challenge gender inequality. 
Ira Shor (1992), a pioneer in critical education, relates critical pedagogy to democracy and empowerment, advocating the connection to lived experiences. Stromquist $(1995 ; 2006)$ adds that the empowerment process should question old beliefs, their context and power relations for a critical understanding of one's reality, perceiving its oppression and challenging inequality. Kabeer (1999) and Mosedale (2005) also address this awareness, who advocates questioning the social order in their environment rather than accepting it as natural. The promotion of this critical capacity is critical for women to act against pre-established societal prejudices.

The combination of critical thinking with spatial thinking is referred to by Minsung Kim \& Robert Bednarz (2013) as critical spatial thinking. Gryl \& Jekel (2012) relate critical spatial thinking and civic participation, stating that pedagogies addressing critical spatial thinking are essential for spatial citizenship. By questioning its context and the relational processes that arise from it, the practice of critical spatial thinking promotes the identification and recognition of existing limitations. It can encourage the sense of responsibility to participate in the community or in collective actions that influence civil society (Adler \& Goggin, 2005) and the ability to express and defend civic causes, thinking globally, thinking "we" rather than individual (Vreese, 2007; Bachen et al. 2008). This engagement in civic life has in itself contained social and spatial scope, with social inequalities being produced in and through space. Civic engagement thus implies recognizing oneself as an integral part of a community, as a citizen with awareness of social issues, and understanding relationships such as spatial dependency or spatial heterogeneity.

The process of sharing emotions, experiences, and lived experiences in the community plays a crucial role in women's empowerment, as it allows for identifying and understanding the reasons for oppression. Furthermore, sharing in collaborative processes allows the building of empathic connections and the development of critical analysis of other ideas. Shirley and Linzi (1996) and Patel (1996) link empowerment, collective sharing and critical analysis and stress the importance of having a safe place where this interaction can take place. Collaborative mapping has the potential to be that safe space for sharing, activism, and registration of the various actions.

\subsection{Collaborative mapping as women's activism}

Initially employed as an instrument of military tactics and territorial demarcation, the map had for centuries its conception limited to the male domain.

The development of technology provided several mapping platforms, allowing the development of the capacities of the map and its scope in a collaborative way. Platforms such as CartoDB, CrowdMap, Google Maps, Leaflet, Mapbox, Open Street Map, OpenLayers, Wikimapps, etc., have provided ways and scenarios of experimentation, allowing the elaboration of collaborative maps in real-time, by different people at the same time and located in different places. The particularity of some platforms being "Open source" has allowed the development of digital social innovation actions. Multiple mapping initiatives, from mapping remote places that had never been mapped before (for example, informal settlements), the reporting of problems or inequalities, the visualization of data and dynamics, etc., appeared. It has also allowed exploring the narrative power of the map (Bodenhamer et al. 2015) and making it a facilitating medium for dialogue and civic engagement (Dennis 2006, 2016; Berglund 2008). As the map is both product and process, the mapping process is in this way an "active knowledge constructor" producing territoriality (Crampton \& Krygier, 2006) and place (Perkins \& Thompson, 2005; Perkins, 2007, Parker, 2006).

By allowing the inclusion of diverse views from different genres of socio-spatial practice, the map can identify socio-spatial inequalities, visualize and highlight relationships between social and spatial processes through critical spatial thinking (Gordon et al., 2016). Critical spatial 
thinking reveals relationships between the social and the spatial, and as reflected in collaborative mapping processes, represents an important form of activism.

2.4. Activism, data production and visualization, and collaborative mapping

Since Since 2019 and due to the frightening growth in domestic violence and femicides cases, there has been the growth of a feminist activist movement with a particular focus on Latin American countries and Mexico. The movement explores data gathering, production and visualization in digital maps.

In order to better understand the capacity and reach that critical spatial thinking associated with collaborative mapping can have as a form of feminist activism, we analyze below four collaborative mapping actions carried out in different countries.

\subsection{Malalai Ring, App and Map - Priscila Gomes and Henrique Mendes (2015)}

Brazil is one of the most violent countries for women, according to the UN. Priscila Gomes, an architect, and Henrique Mendes, a programmer, created, in 2015, a ring (Fig.1) with a panic button connected to a free app (Fig.2). They named the ring "Malalai Ring" in honour of Malala Yousafzai, winner of the Nobel Peace Prize. The panic button allows contacting the person designated as the emergency contact, indicating the emergency location. Besides the route sharing function, the app can add data about positive and negative points in the map, such as inadequate lighting, open commerce, schedules, police presence, and building a collaborative map that identifies the safest routes.

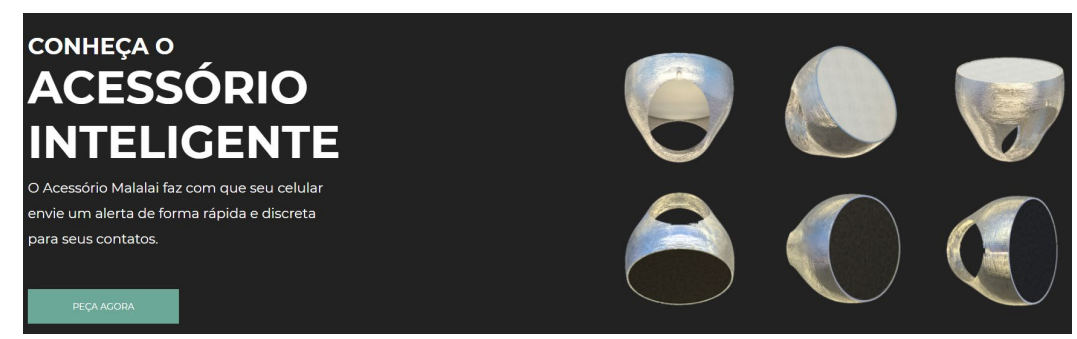

Figure 1. Malalai Ring

Source: https://malalai.com.br/\#steps

\section{3 passos para a sua segurança}

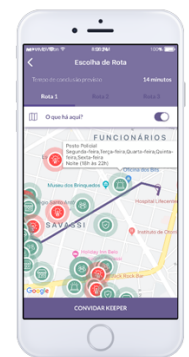

\section{Escolha o caminho mais seguro}
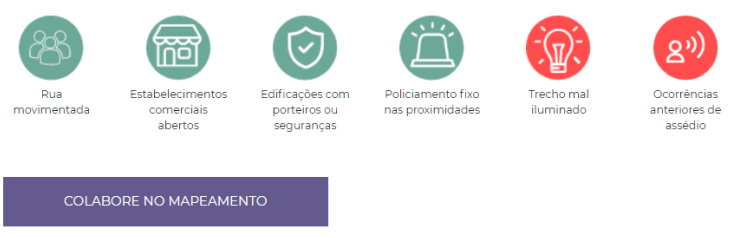

Figure 2. Malalai App

Source: https://malalai.com.br/\#steps

\section{6. "Free to Be" - Plan International (Since 2016)}

In partnership with Crowdspot and the interdisciplinary XYX Lab at Monash University, Plan International has developed a website and app that enables women to report their perception of 
safety. This project was initially designed in 2016 by Plan International Australia in Melbourne as a map-based social survey tool (https://www.plan.org.au/you-can-help/join-the-movementfor-girls-rights/free-to-be/) and further developed through this partnership.

The collaborative mapping initiative was replicated over six weeks in April and May 2018 in Delhi, Kampala, Lima, Madrid and Sydney.

The mapping process was done with the support of girls and young women, asking them to identify and rate places in the city (Fig.3), through Pins ("Good" for places where they felt good and safe and "Bad" where they felt uncomfortable and unsafe). Several professionals involved in the project gathered and added on the digital map the experiences and emotions of the young women. In the five cities, more than 21200 locations were identified, accompanied by 9,292 comments and statements.

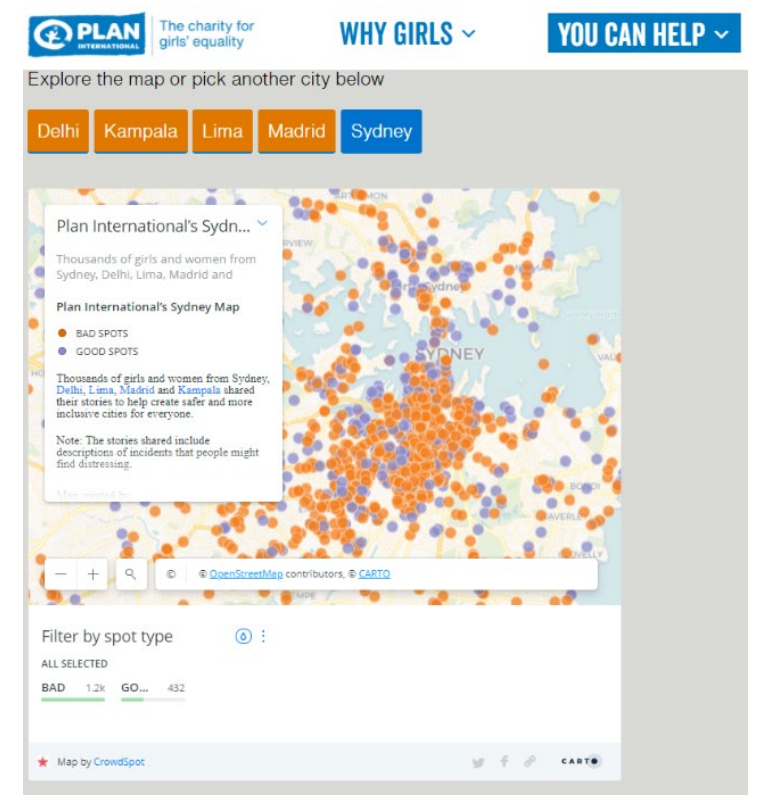

Figure 3. Plan International's Sydney Map

Source: https://www.plan.org.au/you-can-help/join-the-movement-for-girls-rights/free-to-be/

The mapping process of these five cities was compiled and analyzed in the report "Unsafe in the city. The everyday experiences of girls and young women." Noteworthy is the discrepancy of negative PINs in Fig. 4.

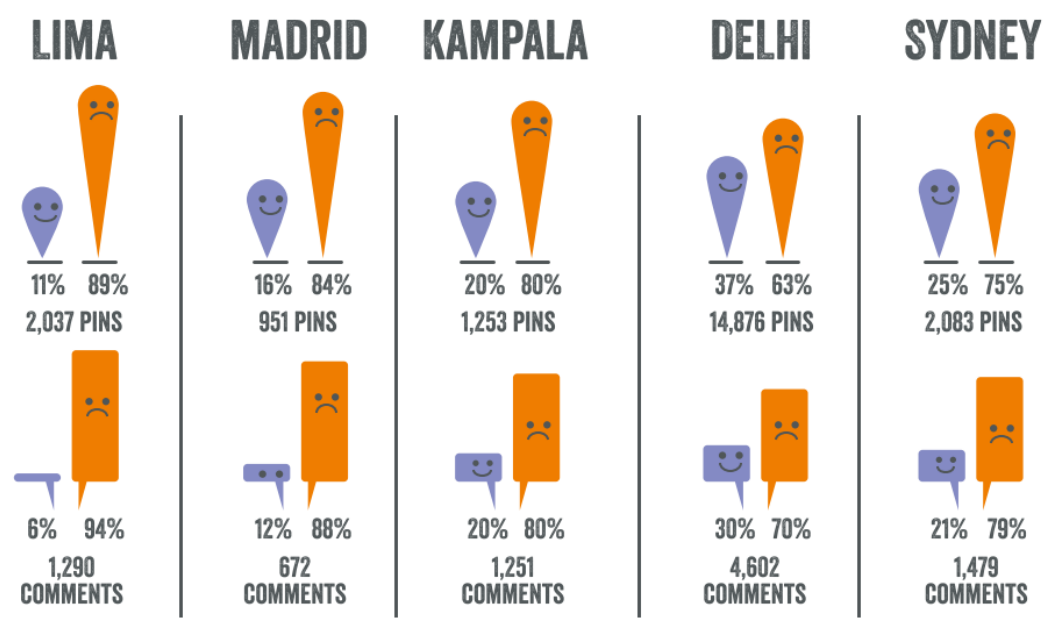

Figure 4. Total number of valid pins and comments, both positive and negative.

Source: Plan International Report, 2018:13. 
They concluded:

"The evidence and testimony of girls and young women in Delhi, Lima, Kampala, Madrid and Sydney makes for grim reading. They have a lot in common. In all five cities they experience sexual harassment and physical violence which ranges from cat-calling to assault on a daily basis. Too many of them, nearly half of the research respondents in some cities, accept the treatment that they receive: "you just have to put up with it", it is what happens, it's "normal". And therein lies the problem. Male behaviour towards girls and women - the groping, leching, name-calling, chasing, bottom-pinching, grabbing, public masturbation and horrendous overall harassment is condoned by society. It is part of life and girls feel powerless to stop it."

(Plan International, 2018:25)

\section{7. \#UnVioladorEnTuCamino - Chilean Collective "Las Tesis" \& Geochicas Collective (2019)}

The same collective mentioned above, Geochicas, geolocated on a collaborative map the several versions of the performance conceived by the Chilean collective "Las Tesis" "UnVioladorEnTuCamino". These artistic performances were intended to protest against violence against women and were composed of a protest song. For the performances, it was requested: feminist convictions, dressing in evening wear and wearing a translucent black blindfold, and the lyrics of the song printed or learned.

The map created "Un Violador En Tu Camino" (Fig. 5) allowed the tracking and visualization of the places where the performance had already taken place and signalled future events.
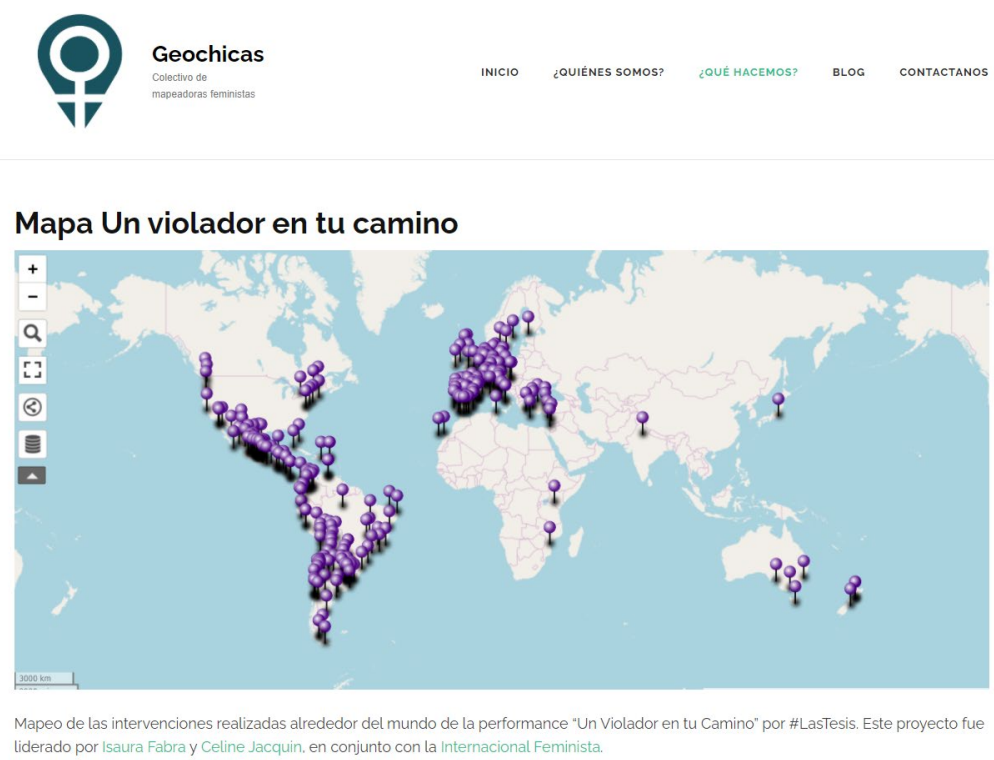

Figure 5. "Un Violador En Tu Camino" map

Source:https:/umap.openstreetmap.fr/es/map/un-violador-en-tu-camino-20192021-actualizado-al2 394247\#2/11.7/12.7

This collective performance was so impactful that it echoed across several digital platforms (García-González, L. \& Bailey, O.G., 2020) and was replicated in several countries. One of the most notable performances was the one held in the Parliament of Turkey by a group of deputies from the opposition to denounces the macho violence and the inactivity of the institutions. Many other actions were subsequently performed, in various countries, as an expression of support and solidarity, generating empowerment (Cuffe, 2019). 


\section{8. «Las calles de las mujeres» - Geochicas Collective (2018)}

The feminist collective GeoChicas (https://geochicas.org/) emerged as a resilience and resistance action, aiming to increase women's participation in mapping using the OpenStreetMap (OSM) platform. This international feminist collective has been developing maps with a gender perspective since 2016. One of the projects they developed was "Las calles de las mujeres" (Fig. 6 ) with data from OpenStreetMap on the Mapbox platform (https:// geochicasosm.github.io/lascallesdelasmujeres/).

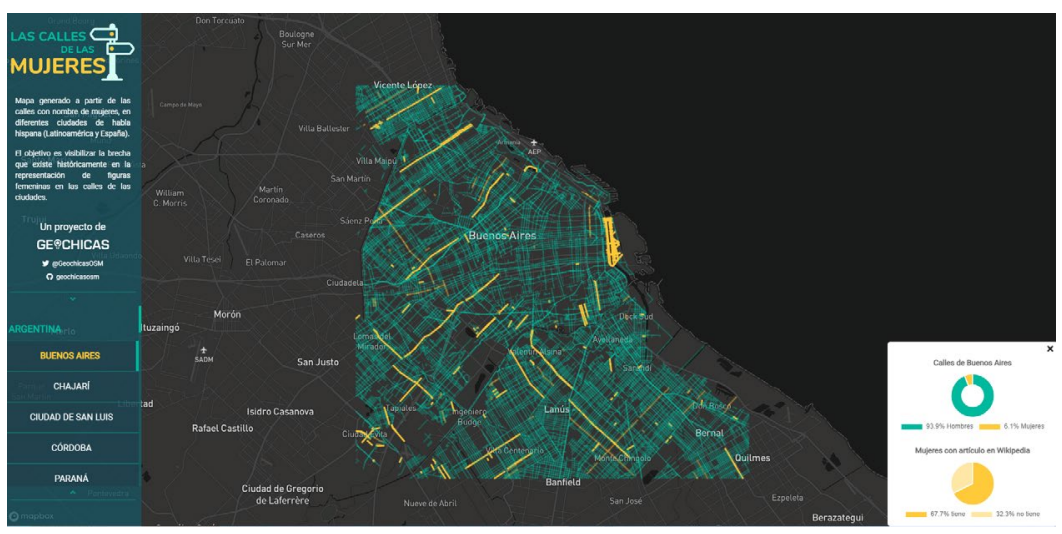

Figure 6. "Las calles de las mujeres" map

Source: https://geochicasosm.github.io/lascallesdelasmujeres/

The project "Las calles de las mujeres" aimed to make visible the gap that historically exists in the representation of women in city streets. The GeoChicas collective mapped the street names of 12 cities in Latin America and Spain and demonstrated the low number of women's street names. For example, $83.7 \%$ of streets had men's names in Barcelona, and in Buenos Aires, only $6.1 \%$ of streets had women's names. Havana had the smallest disparity, where only $37.8 \%$ of its streets had women's names.

This activist mapping action highlighted the importance of historical narratives where women should not be excluded from collective memory.

\section{Results and Discussion}

Four collective action projects were analyzed based on critical spatial thinking, which highlighted various inequalities and injustices. The power of collective mapping as an expression of critical spatial thinking was explored through the sharing, representation and visualization of experiences.

The first three examples presented georeferenced individual expressions on an issue that impacts the women's lives, violence in urban spaces, through a plurality of voices and by structuring themselves into networks of digital activism. Finally, the fourth example presented showed the importance of data visualization, built collaboratively, in disseminating a message and activist positioning in how women have historically had been little represented.

The repercussion of projects has demonstrated how critical spatial thinking is also related to the experimentation of new communication processes that recognize and reinforce the relevance of individual perspectives in urban spaces that can enrich a more active and activist collective "voice".

\section{Conclusion}

Reinforcing the "Right to the City" concept of Henri Lefebvre (1991) and David Harvey (2008), this paper explored the need to encourage critical spatial thinking capable of promoting active citizenship actions by identifying weaknesses and threats to women's safety. 
The process and act of mapping and being mapped plays a leading role in making visible and giving visibility, particularly on digital platforms. To be mapped and to appear on online maps means to "exist".

The four mapping actions addressed here have documented activist and ethnographic community actions and reflected and pointed out gender inequalities and oppression. They also showed how gender empowerment through critical spatial thinking reflects in urban activism that, extrapolating to the digital level (social networks and media), reaches international echoes and repercussions. For this reason, it is crucial to identify the fracturing points in cities, to question and show how different urban territories are seen and lived, taking into account gender diversity and the intersection with other variables such as age, origin, sexual identity.

The initiatives presented here highlight the potential of collaborative mapping processes to promote and develop critical spatial consciousness, stimulate collective action, and represent socio-spatial inequalities in mapping actions, where new forms of collective knowledge construction emerged.

Developing critical spatial thinking from the perspective of gender equality connected to empathy also allows developing social awareness and increasing spatial consciousness. It is crucial to enable and encourage this critical spatial thinking about women's environment to understand and recognize the existent limitations and constraints, such as gender bias, social exclusion, spatial segregation and cultural stigmatization, factors that make it impossible to achieve the goal 11 of the United Nations Agenda 2030, concerning the need to make cities and human settlements inclusive, safe, resilient and sustainable.

\section{Acknowledgements}

The author's research is funded by Portuguese National Funds, the Foundation for Science and Technology (FCT) with the reference [CEECIND/04642/2017].

\section{References}

Adler, R., \& Goggin, J. (2005). What Do We Mean By “Civic Engagement”? Journal of Transformative Education, 236-253.

Bachen, C., C. Raphael, K.-M., K. Lynn, McKee, and J. Philippi. (2008). "Civic Engagement, Pedagogy, and Information Technology on Web Sites for Youth." Political Communication 25 (3): 290-310.

Berglund, U. (2008). Using Children's GIS Maps to Influence Town Planning. Children, Youth and Environments 18 (2): 110-132.

Bodenhamer, D., Corrigan, J. and Trevor, H. (2015). Deep Maps and Spatial Narratives. Bloomington: Indiana University Press.

Crampton, J. W. \& Krygier, J. (2006). An introduction to critical cartography. ACME 4 (1): 11-53.

Cuffe, S. (2019). Chile's 'A Rapist in Your Path' Chant Hits 200 Cities: Map. [WWW document]. URL https://www.aljazeera.com/news/2019/12/chile-rapist-path-chant-hits200-cities-map-191220200017666.html [accessed 21 July 2020].

Dennis, Jr. (2006). Prospects for Qualitative GIS at the Intersection of Youth Development and Participatory Urban Planning. Environment and Planning A 38 (11): 2039-2054.

Dennis, E.; Elwood, S. \& Mitchell, K. (2016). Critical Spatial Learning: Participatory Mapping, Spatial Histories, and Youth Civic Engagement. Children s Geographies. DOI: $10.1080 / 14733285.2015 .1136736$ 
García-González, L. \& Bailey, O.G. (2020). Análisis de la protesta global \#UnVioladorEnTuCamino. TRAMAS. Subjetividad Y Procesos Sociales, 1(53), 67-100. Avaiable at: https://tramas.xoc.uam.mx/index.php/tramas/article/view/907

Goodchild, M.F., Janelle, D.G. 2010. Toward critical spatial thinking in the social sciences and humanities. GeoJournal 75, 3-13 (2010). https://doi.org/10.1007/s10708-010-9340-3

Gordon, E., Elwood, S. and Mitchell, K. (2016). Critical Spatial Learning: Participatory Mapping, Spatial Histories, and Youth Civic Engagement. Children's Geographies 14, 5, 558-572.

Gryl, I., Jekel, T. (2012). Re-Centering Geoinformation in Secondary Education: Toward a Spatial Citizenship Approach. Cartographica 47 (1): 18-28.

Harvey, D. (2008): "The Right to the City", New Left Review 53: 23-39.

Kabeer, N. (1999). Resources, Agency, Achievements: Reflections on the Measurement of Women's Empowerment. Development and Change, 30(3), 435-464. http://dx.doi.org/ 10.1111/1467-7660.00125

Kim, M. \& Bednarz, R. (2013). Development of Critical Spatial Thinking through GIS Learning. Journal of Geography in Higher Education, 37(3), 350-366. https://doi.org/ 10.1080/03098265.2013.769091

Lefebvre, Henri. (1991). The Production of Space. Oxford: Blackwell.

Mosedale, S. (2005). Assessing women's empowerment: Towards a conceptual framework. Journal of International Development, 17, 243-257.

Parker, B. (2006). Constructing Community Through Maps? Power and Praxis in Community Mapping. Professional Geographer, Vol. 58, No 4, pp. 470-484.

Perkins, C. \& Thompson, A. (2005). Mapping for Health: Walking and Cycling Maps of the City. North West Geography, Vol. 5, N ${ }^{\mathrm{o}}$ 1, pp. 16-23.

Perkins, C. (2007). Community Mapping. The Cartographic Journal, Vol. 44, № 2, pp. 127137.

Shirley, W. \& Linzi, M. (1996). Gender in popular education. Methods for empowerment. Shirley, W. \& Linzi, M. (Eds.). London: New Jersey: CACE Publications.

Shor, I. (1992). Empowering education. Chicago: The University of Chicago Press.

Stromquist, N. (1995). The Theoretical and Practical Bases for Empowerment, in Women, Education and Empowerment: Pathways Towards Autonomy, Report of International Seminar, edited by Carolyn Medel Anonuevo, UNESCO Institute for Education, Hamburg.

Stromquist, N. (2006). Gender, education and the possibility of transformative knowledge. Compare: A Journal of Comparative and International Education, 36(2), 145-161. http://dx.doi.org/10.1080/03057920600741131

Patel. S. (1996). From a seed to a tree: building community organization in India's cities. In Shirley, W. \& Linzi, M. (Eds.), Gender in popular education. Methods for empowerment. 95-109. London: New Jersey: CACE Publications.

Plan International. (2018). Unsafe in the city. The everyday experiences of girls and young women. Avaiable at https://plan-international.org/unsafe-city

United Nations Development Programme. (2020). Tackling Social Norms: A game Changer for Gender Inequalities. UN. https://doi.org/10.18356/ff6018a7-en

de Vreese, C. (2007). Digital Renaissance: Young Consumer and Citizen? Annals of the American Academy of Political and Social Science 611 (1): 207-216. 